\title{
Single nucleotide polymorphisms associated with postoperative inadequate analgesia after single-port VATS in Chinese population
}

\author{
Xiufang Xing, Yongyu Bai, Kai Sun and Min Yan * (D)
}

\begin{abstract}
Background: Postoperative inadequate analgesia following video-assisted thoracoscopic surgery (VATS) is a common and significant clinical problem. While genetic polymorphisms may play role in the variability of postoperative analgesia effect, few studies have evaluated the associations between genetic mutations and inadequate analgesia after single-port VATS.

Methods: Twenty-eight single nucleotide polymorphisms (SNPs) among 18 selected genes involved in pain perception and modulation were genotyped in 198 Chinese patients undergoing single-port VATS. The primary outcome was the occurrence of inadequate analgesia in the first night and morning after surgery which was defined by a comprehensive postoperative evaluation. Multivariable logistic regression analyses were used to identify the association between genetic variations and postoperative inadequate analgesia.

Results: The prevalence of postoperative inadequate analgesia was $45.5 \%$ in the present study. After controlling for age and education level, association with inadequate analgesia was observed in four SNPs among three genes encoding voltage-gated sodium channels. Patients with the minor allele of rs33985936 (SCN11A), rs6795970 (SCN10A), and 3312G > T (SCN9A) have an increased risk of suffering from inadequate analgesia. While the patients carrying the minor allele of rs11709492 (SCN11A) have lower risk experiencing inadequate analgesia.

Conclusions: We identified that SNPs in SCN9A, SCN10A, and SCN11A play a role in the postoperative inadequate analgesia after single-port VATS. Although future larger and long-term follow up studies are warranted to confirm our findings, the results of the current study may be utilized as predictors for forecasting postoperative analgesic effect for patients receiving this type of surgery.
\end{abstract}

Trial registration: This study was retrospectively registered in the ClinicalTrials.gov Registry (NCT03916120) on April 16, 2019.

Keywords: Postoperative pain, Single nucleotide polymorphism, Single-port video-assisted thoracoscopic surgery

\section{Background}

Thoracotomy is considered to be one of the most painful of surgical procedures [1]. Even though video-assisted thoracoscopic surgery (VATS) is less invasive and is generally expected to induce lower pain intensity, the moderate to severe postoperative pain remains common after VATS $[2,3]$. The postoperative pain not only causes

\footnotetext{
* Correspondence: zryanmin@zju.edu.cn

Department of Anesthesiology and Pain Medicine, Second Affiliated Hospital,

Zhejiang University School of Medicine, No.88 Jiefang Road, Hangzhou 310009, China
}

respiratory complications but negatively affects long-term rehabilitation $[4,5]$.

Multiple factors have been reported to affect pain sensitivity after surgery, such as age, gender, ethnicity, and type of surgery [6]. Recent advances in genetic research have shown that genetic polymorphisms may also play a role in the variability of pain perception [7-9]. Opioid receptor mu 1 (OPRM1) encodes the mu opioid receptor in humans, and plays an important role in endogenous pain modulation and opioid analgesia. Four single nucleotide polymorphisms (SNPs) in OPRM1 were found 
significantly associated with higher pain intensity after thoracotomy [8]. Zhonghai Zhao et al. indicated that patients with mutant homozygous rs2032582 and rs1128503 loci in the $A B C B 1$ gene consumed more sufentanil at $6 \mathrm{~h}$, $24 \mathrm{~h}$ and $48 \mathrm{~h}$ after thoracoscopic-assisted radical resection [9]. Besides, patients with the UGT2B7* $2 / * 2$ genotype had a higher risk of suffering severe pain $48 \mathrm{~h}$ after surgery [10]. Jin Ma et al. found that rs1718125 polymorphism in P2RX7 gene had significant association with postoperative pain intensity and the consumption of fentanyl in patients undergoing lung resection [11].

The mechanism of acute pain after thoracotomy has not been fully illuminated, but it is believed to be caused by a variety of factors including the local damage of rib and skin incision, the inflammation caused by injury, and the acute intercostal neuralgia $[1,12]$. The multifactorial nature of postoperative pain suggests that a number of distinct genetic factors may contribute to the variability in pain perception and analgesic effect after thoracotomy. Although more and more genetic polymorphisms have been identified as risk factors for rare and common pain syndromes $[13,14]$, most of these genes have not been studied in thoracotomy subjects.

In the present study, except for OPRM1, $A B C B 1$, $U G T 2 B 7$, and $P 2 R X 7$, we selected other 14 genes known to be involved in systems related to pain perception and modulation based on evidence in the literature. The selected genes have been related to the ion channels (SCN9A, SCN10A, SCN11A, KCNJ6, TRPV1, and CACN A1E) [15-20], dopaminergic system (COMT, DRD2) [21, 22], purinergic receptor (P2RY12) [23], adrenergic receptor (ADRB1) [24], estrogen receptor (ESR1) [25], serine/ threonine kinase (TAOK3) [26], growth factors (TGFB1) [27], and transcription factor (CREB1) [28]. The aim of the present study was to evaluate the association of common SNPs among aforementioned genes with the inadequate analgesia after single-port VATS.

\section{Methods}

The current prospective study was approved by the Ethics Committee of the Second Affiliated Hospital of Zhejiang University School of Medicine, Hangzhou, Zhejiang, China, and the protocol was registered in the ClinicalTrials.gov Registry (NCT03916120). All subjects signed informed consent documents prior to enrollment.

\section{Patient characteristics}

Two hundred Thirty-two subjects were recruited from consecutive patients undergoing selective lung section with single-port VATS performed by one attending surgeon at the Second Affiliated Hospital of Zhejiang University School of Medicine between July 2018 and January 2019. The detailed surgical procedure was previously described [29]. The criteria for inclusion in the study were age from
18 to 70, ASA classification I to III, and voluntarily received patient-controlled intravenous (PCIA) treatment. The exclusion criteria included the following: (1) history of mental illness, chronic pain, and alcohol or drug abuse; (2) remarkably abnormal liver and/or kidney function (more than two times of the normal); (3) allergy to related opioid drugs; (4) women during pregnancy or lactation.

\section{Anesthesia protocol}

All patients received general anesthesia under standard protocol. Specifically, general anesthesia was induced with midazolam $\left(0.2 \mathrm{mg}^{*} \mathrm{~kg}-1\right)$, sufentanil $(10 \mu \mathrm{g} * \mathrm{~kg}-1)$, and etomidate $\left(0.3 \mathrm{mg}^{*} \mathrm{~kg}-1\right)$. Cisatracurium besilate $\left(0.15 \mathrm{mg} \mathrm{kg}^{*} \mathrm{~kg}\right.$ 1) was administered to induce a neuromuscular blockade for tracheal intubation. Anesthesia was continuously maintained with sevoflurane, propofol, and remifentanil. Cisatracurium was bloused as needed. During the surgery, standardized monitoring and bispectral index were applied. Central venous catheterization $(\mathrm{CVC})$ and A-line were implemented for each patient. Before closure of the thoracic incision, surgeons performed a three-site intercostal nerve block with $0.75 \% 10 \mathrm{~mL}$ ropivacaine under thoracoscope. At the end of surgery, pentazocine $5 \mathrm{mg}$ and tropisetron $5 \mathrm{mg}$ were administered by the anesthetist. Immediately after surgery, PCIA was connected to the CVC. Then, patients were transferred to postanesthesia care unit (PACU) for recovery where their vital signs were continuously monitored.

\section{Postoperative pain management}

Each subject was extubated at PACU when vital signs stabilized. Patients were asked every $10-15 \mathrm{~min}$ after they were awake enough whether they needed pain medication until they became conscious enough to use the PCIA. If the patients felt moderate or severe pain (visual analog scale [VAS] $40-100,0=$ no pain to $100=$ intense pain), they were given $40 \mathrm{mg}$ dynastat until their VAS was $\leq 30$. Patients were excluded if they received dynastat as rescue analgesia at PACU. PCIA was administered with a bolus doses of $0.002 \mathrm{mg} / \mathrm{kg}$ hydromorphone permitted every $8 \mathrm{~min}$. In case of PCIA analgesic inadequate (VAS $\geq 40$ ), dynastat $40 \mathrm{mg}$ would be administered as an alternative rescue modality. Tropisetron 5 $\mathrm{mg}$ or palonosetron $0.25 \mathrm{mg}$ could be administered to combat postoperative nausea and vomiting.

\section{Data collection and follow-up}

During the preoperative interview, demographic characteristics, educational background, work type, and history of cigarette smoking and alcohol consumption were recorded. Besides, the general sleep quality within 1 month was recorded by a scale with three levels (poor, fair, and good). At the same time, patients were instructed on how to use the VAS to describe the pain they were experiencing, and how 
to use the PCIA device to control the pain when necessary. After surgery, the intraoperative parameters including surgery type and duration, anesthesia duration, lymphadenectomy, adhesion loosening, and pathologic diagnosis were also recorded.

During the follow-up period, VAS at rest and during coughing was recorded on the first morning (8:00 a.m.) after surgery. In the meantime, the use of rescue analgesia, postoperative sleep quality, and the degree of satisfaction (bad, fair, good, and excellent) to the pain management were recorded.

\section{End-points}

The primary outcome was the occurrence of postoperative inadequate analgesia. Once patient experience at least one of the following situations during the first night and morning after surgery: require extra analgesic drug; report moderate-to-severe pain (VAS $\geq 4$ ) at rest; report poor sleep quality; report bad satisfaction with pain control, they were defined as postoperative inadequate analgesia.

\section{Genotype analysis}

Blood samples were collected in tubes containing ethylenediaminetetraacetic acid $1 \mathrm{~h}$ after CVC was implemented and were then stored at $-80^{\circ} \mathrm{C}$. Genomic DNA was extracted from whole blood for genetic analysis by using Blood Genomic DNA Mini Kit (Biomed Corporation, China) according to the manufacturer's recommendations. DNA samples were then stored at $-20^{\circ} \mathrm{C}$. SNPs were genotyped using a $\mathrm{KASP}^{\mathrm{m} w \mathrm{~s}}$ genotyping assay (Rui Biotechnology, Beijing, China) as previously described [30, 31].

Quality control was performed to ensure the robust genetic association: SNPs with call rates of $<95 \%$, Minor Allele Frequency (MAF) $<0.05$, or Hardy-Weinberg equilibrium (HWE) of $p<0.05$ were excluded. Linkage disequilibrium (LD) was calculated from the patients' genotypes. When strong LD $\left(\mathrm{r}^{2}>0.9\right)$ was present in one gene, we only included one SNP from each pairs of SNP in the association study. Finally, there were 28 SNPs among the 18 candidate genes passed all quality control filters. (See Table 1 ).

\section{Statistical analysis}

Statistical analysis was completed with the SPSS 24.0 (SPSS Inc., Chicago, IL). Continuous variables were expressed as means and standard deviations (SDs) or as medians and interquartile range, and categorical variables as counts and percentages. Differences between two groups were evaluated by Student's t-test or the Mann-Whitney test for continuous variables, and Chi-squared test or Fisher's exact test for categorical variables. For analyzing the association between SNPs and inadequate analgesia, odds ratios (ORs) and $95 \%$ confidence intervals $(\mathrm{CI})$ were calculated by logistic regression analysis adjusted for potential risk factors. Four genetic models (co-dominant, dominant, recessive and overdominant) were evaluated for association of polymorphisms with risk of inadequate analgesia. HWE was assessed by SNPStats software [32]. The linkage disequilibrium and pairwise LD coefficients were implemented with Haploview 4.2 (Daly Lab: Cambridge, MA, USA, 2008). $P$ value $<0.05$ was considered significant.

Power analysis was done using QUANTO (University of Southern California, Los Angeles, CA). For the analyses of associations with postoperative inadequate analgesia, with the sample size of 198 and a modest Type I error rate of $5 \%$, the analysis had more than $90 \%$ power to detect an OR of 2.15 for SNPs with an MAF $\geq 0.11$ under dominant model and more than $99 \%$ power to detect an OR of 0.41 for SNPs with an MAF $\geq 0.26$ under recessive model.

\section{Results}

\section{Patient characteristics}

From July 2018 to January 2019, a total of 232 patients underwent single-port VATS at our center. Two hundred eleven patients met the inclusion criteria voluntarily participate in this study. Thirteen patients were withdrawn due to conversion to open surgery $(n=3)$ or expectant treatment $(\mathrm{n}=3)$, transferred to the intensive care unit after operation $(n=2)$, and received rescue analgesics in PACU $(n=5)$. Therefore, the data from 198 patients entered the final analysis as shown in Fig. 1.

The overall demographic and clinical characteristics are shown in Table 2 and Table 3. All enrolled patients were Chinese population. The baseline cohort comprised 115 females (58.1\%) and 83 males (41.9\%), aged 37 to 70 years (mean 58.0 years). Postoperative inadequate analgesia was observed in 90 patients (90/198, 45.5\%), including 66 patients with moderate-to-severe pain at rest (VAS $\geq 4$ ), 45 patients required extra analgesic drug, 68 patients had bad sleep quality, and 30 patients were unsatisfactory to the pain management. Except for age and education level, there were no significant differences regarding demographic variables and clinical characteristics between patients with and without inadequate analgesia. The patients with inadequate analgesia were significant younger, and had higher education level than patients without inadequate analgesia. These variables were included as covariates in the regression model of genetic association analysis.

\section{Association analysis}

The genotyping call rate was $100 \%$. All the selected SNPs met the HWE criterion $(p<0.05)$ and without low MAF $(p<0.05)$. Strong LDs in SCN11A (Additional file 1: Figure S1) were identified in our sample, and we included only one SNP from each pair of SNP in the association study. Thus, 28 SNPs among 18 genes were assessed for further association analysis. 
Table 1 Description of all single nucleotide polymorphisms analyzed

\begin{tabular}{|c|c|c|c|c|c|}
\hline Gene & Polymorphism & Functional Consequence & Variant & Major/minor allele frequency & Hardy Weinberg $p$-value \\
\hline \multirow[t]{2}{*}{$\overline{A B C B 1}$} & rs1045642 & Synonymous codon & $A>G$ & $0.62 / 0.38$ & 0.37 \\
\hline & rs1128503 & Synonymous codon & $A>G$ & $0.67 / 0.33$ & 0.63 \\
\hline \multirow[t]{2}{*}{$A D R B 1$} & rs1801252 & Missense & $A>G$ & $0.83 / 0.17$ & 0.46 \\
\hline & rs1801253 & Missense & $G>C$ & $0.74 / 0.26$ & 1 \\
\hline CACNATE & rs3845446 & Intron variant & $\mathrm{T}>\mathrm{C}$ & $0.7 / 0.3$ & 0.61 \\
\hline \multirow[t]{2}{*}{ COMT } & rs4633 & Synonymous codon & $C>T$ & $0.72 / 0.28$ & 0.86 \\
\hline & rs4680 & Missense & $G>A$ & $0.72 / 0.28$ & 1 \\
\hline DRD2 & rs6277 & Synonymous codon & $G>A$ & $0.94 / 0.06$ & 0.55 \\
\hline ESR1 & rs9340799 & Intron variant & $A>G$ & $0.81 / 0.19$ & 0.25 \\
\hline \multirow[t]{2}{*}{ KCNJ6 } & rs6517442 & Upstream variant & $C>T$ & $0.73 / 0.27$ & 0.07 \\
\hline & rs2070995 & synonymous codon & $\mathrm{T}>\mathrm{C}$ & $0.61 / 0.39$ & 0.55 \\
\hline \multirow[t]{3}{*}{ OPRM1 } & rs1799971 & Intron variant & $A>G$ & $0.69 / 0.31$ & 0.50 \\
\hline & rs677830 & Intron variant & $C>T$ & 0.89/0.11 & 0.46 \\
\hline & rs540825 & Intron variant & $A>T$ & 0.92/0.08 & 1 \\
\hline$P 2 R X 7$ & rs7958311 & Intron variant & $G>A$ & $0.52 / 0.48$ & 0.67 \\
\hline P2RY12 & rs3732765 & Intron variant & $G>A$ & $0.87 / 0.13$ & 1 \\
\hline \multirow[t]{2}{*}{ SCN11A } & rs33985936 & Missense & $C>T$ & 0.89/0.11 & 0.48 \\
\hline & rs11709492 & Intron variant & $C>T$ & $0.74 / 0.26$ & 0.71 \\
\hline SCN1OA & rs6795970 & Missense & $A>G$ & $0.86 / 0.14$ & 0.38 \\
\hline \multirow[t]{3}{*}{ SCN9A } & rs6746030 & Intron variant & $A>G$ & $0.95 / 0.05$ & 0.36 \\
\hline & rs4286289 & Intron variant & $C>A$ & $0.56 / 0.44$ & 1 \\
\hline & $3312 G>T$ & Missense & $\mathrm{G}>\mathrm{T}$ & $0.9 / 0.1$ & 0.69 \\
\hline \multirow[t]{2}{*}{ TAOK3 } & rs795484 & Intron variant & $\mathrm{T}>\mathrm{C}$ & $0.68 / 0.32$ & 0.74 \\
\hline & rs1277441 & Intron variant & $G>A$ & $0.59 / 0.41$ & 0.14 \\
\hline TGFB1 & rs1800469 & Downstream variant & $A>G$ & $0.51 / 0.49$ & 0.26 \\
\hline TRPV1 & rs8065080 & Missense & $\mathrm{T}>\mathrm{C}$ & $0.64 / 0.36$ & 0.22 \\
\hline UGT2B7 & rs7439366 & Missense & $\mathrm{T}>\mathrm{C}$ & $0.69 / 0.31$ & 0.87 \\
\hline CREB1 & rs2952768 & None & $\mathrm{T}>\mathrm{C}$ & $0.57 / 0.43$ & 0.77 \\
\hline
\end{tabular}

Abbreviations: $A B C B 1$ ATP binding cassette subfamily B member 1, ADRB1 adrenoceptor beta 1, CACNA1E calcium voltage-gated channel subunit alpha1 E, COMT catechol-O-methyltransferase, CREB1 CAMP responsive element binding protein 1, DRD2 dopamine receptor D2, ESR1 estrogen receptor 1, KCNJ6 potassium voltage-gated channel subfamily J member 6; OPRM1 opioid receptor mu 1, P2RX7 purinergic receptor P2X 7; P2RY12 purinergic receptor P2Y12, SCN11A sodium voltage-gated channel alpha subunit 11; SCN10A sodium voltage-gated channel alpha subunit 10, SCN9A sodium voltage-gated channel alpha subunit 9, TAOK3 TAO kinase 3, TGFB1 transforming growth factor beta 1, TRPV1 transient receptor potential cation channel subfamily $V$ member 1, UGT2B7 UDP glucuronosyltransferase family 2 member B7

The distribution of the allele and genotype frequencies of the remaining 28 SNPs in patients with and without inadequate analgesia is summarized in Additional file 2: Table S1. Significant associations between genetic mutations and postoperative inadequate analgesia were detected in six SNPs among five genes (ESR1, P2RY12, SCN11A, SCN9A, and $T A O K 3$ ) by the logistic regression (see Table 4). After adjusting for potential confounders, four SNPs remained significant: rs33985936 (SCN11A), rs11709492 (SCN11A), rs6795970 (SCN10A), and 3312G > T (SCN9A).

For SCN11A, two SNPs (i.e., rs33985936, rs11709492) were associated with the occurrence of inadequate analgesia. For rs33985936, individuals who carried the rare $\mathrm{T}$ allele ( $\mathrm{TC}+$ TT vs. CC) had a 2.15-fold increase in the odds of reporting inadequate analgesia. The rare $\mathrm{T}$ allele carriers of rs11709492 were found to be associated with decreased risk of inadequate analgesia (OR $=0.41,95 \% \mathrm{CI}$ : $0.22-0.77, p=0.005)$.

For SCN10A rs6795970, patients with GA/ AA genotype had a 2.14-fold increase in the odds of reporting inadequate analgesia compared to GG genotype.

For SCN9A $3312 \mathrm{G}>\mathrm{T}$, patients who were heterozygous or homozygous for the rare $\mathrm{T}$ allele $(\mathrm{TG}+\mathrm{TT}$ vs GG) had a 2.85 -fold increase in the odds of reporting postoperative inadequate analgesia.

\section{Discussion}

In the present study, the incidence of postoperative inadequate analgesia in patients undergoing single- 


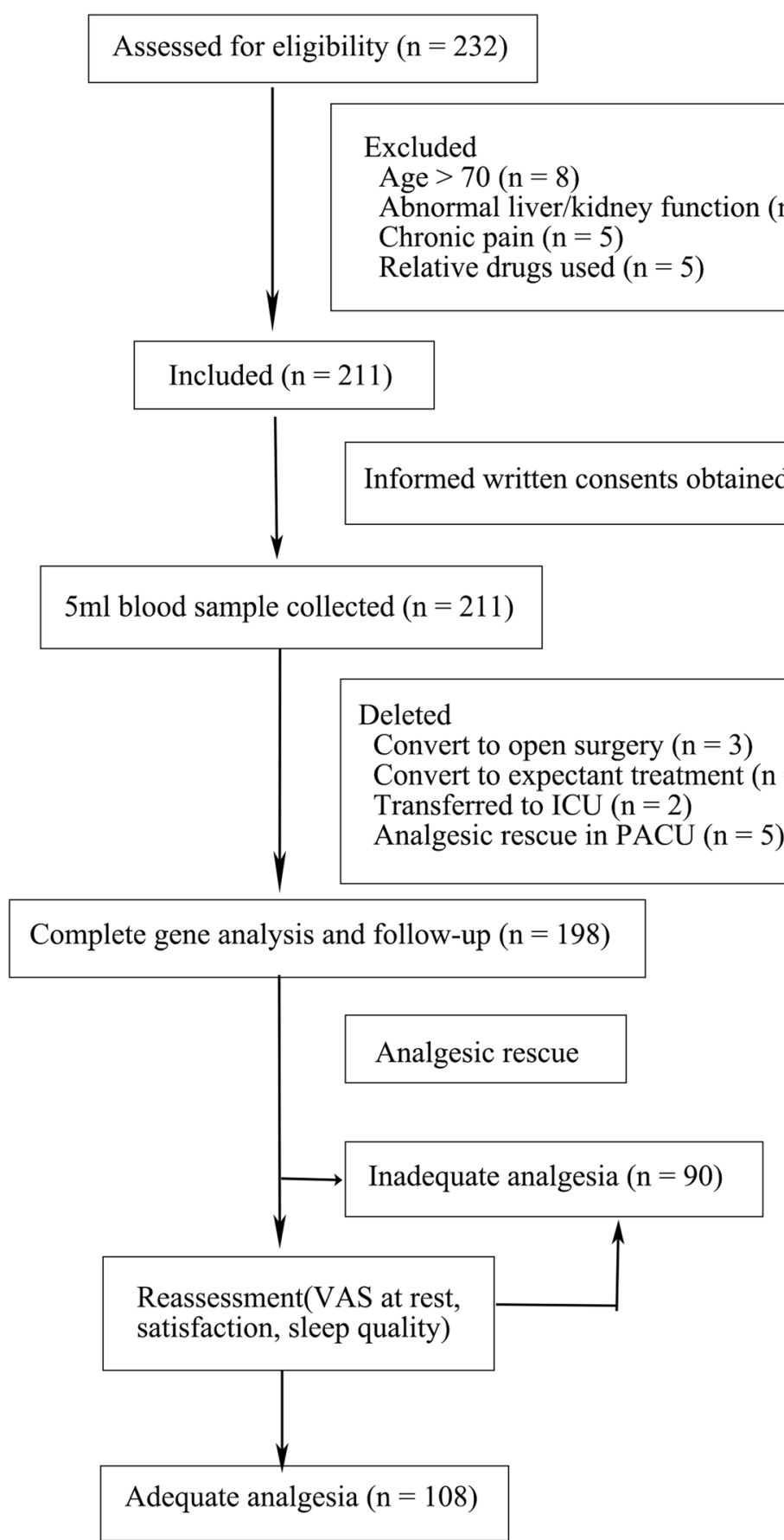

Fig. 1 Flowchart for inclusion and follow-up in the study. Abbreviations: ICU = intensive care unit; PACU = postanesthesia care unit; VAS=visual analog scale

port VATS was 45.5\%. Twenty-eight SNPs among 18 genes involved in pain perception and modulation were selected to test the association between genetic polymorphisms and postoperative inadequate analgesia. After adjusting for confounding factors, significant association with inadequate analgesia was found in four SNPs (rs11709492, rs33985936, rs6795970, and $3312 \mathrm{G}>\mathrm{T}$ ) of genes encoding voltage-gated sodium channels.

Although numerous measures have been developed for the management of postoperative pain, the proportion of patient experience moderate to severe postoperative pain after thoracotomy was relatively high [2]. In the present study, the inadequate analgesia was happened in $45.5 \%$ 
Table 2 Distribution of socio-demographic characteristics between patients with and without postoperative inadequate analgesia

\begin{tabular}{|c|c|c|c|}
\hline Variables & Adequate analgesia $(n=108)$ & Inadequate analgesia $(n=90)$ & P-Value \\
\hline Age (y) (mean \pm SD) & $60.08 \pm 6.79$ & $55.42 \pm 9.03$ & $<0.001$ \\
\hline Sex & & & 0.11 \\
\hline Female & $70(63.1 \%)$ & $45(51.7 \%)$ & \\
\hline Male & $41(36.9 \%)$ & $42(48.3 \%)$ & \\
\hline BMI (mean $\pm S D)$ & $22.86 \pm 2.84$ & $23.10 \pm 2.57$ & 0.54 \\
\hline Weight (mean \pm SD) & $60.92 \pm 9.34$ & $63.31 \pm 9.30$ & 0.07 \\
\hline History of Cigarette Smoking & & & 0.62 \\
\hline Yes & $22(20.4 \%)$ & $21(24.1 \%)$ & \\
\hline No & $86(79.6 \%)$ & $69(75.9 \%)$ & \\
\hline History of Alcohol Consumption & & & 1.00 \\
\hline Yes & $24(22.2 \%)$ & $10(22.2 \%)$ & \\
\hline No & $84(77.8 \%)$ & $70(77.8 \%)$ & \\
\hline Educational Level & & & $<0.001$ \\
\hline Low & $52(48.1 \%)$ & $23(25.6 \%)$ & \\
\hline Medium & $46(42.6 \%)$ & $35(38.9 \%)$ & \\
\hline High & $10(9.3 \%)^{*}$ & $32(35.6 \%)$ & \\
\hline Exercise & & & 0.26 \\
\hline Yes & $49(45.4 \%)$ & 48 (53.3\%) & \\
\hline No & $59(54.6 \%)$ & $42(46.7 \%)$ & \\
\hline Preoperative Sleep Quality & & & 0.33 \\
\hline Poor & $18(16.7 \%)$ & $21(23.3 \%)$ & \\
\hline Fair & $43(39.8 \%)$ & $28(31.1 \%)$ & \\
\hline Good & $47(43.5 \%)$ & $41(45.6 \%)$ & \\
\hline Major Surgery within 2 Years & & & 0.51 \\
\hline Yes & $9(8.3 \%)$ & $10(11.1 \%)$ & \\
\hline No & 99 (91.7\%) & $80(88.9 \%)$ & \\
\hline
\end{tabular}

Abbreviations: $\mathrm{BMI}=$ body mass index; $\mathrm{SD}=$ standard deviation

of patients who received intercostal nerve block and standard PCIA with hydromorphone after single-port VATS. This result was consistent with previous reports $[3,33]$. Considering some patients were unwilling to take any extra analgesic drug even though they were unsatisfactory to the analgesia effect or their sleep was disturbed by pain, we defined postoperative inadequate analgesia as not only patients with moderate to severe pain and required extra analgesic drug, but also patients with bad sleep quality and low satisfaction. This definition comprehensively comprises the real patients with inadequate analgesia.

Our results indicated that four SNPs in genes encoding voltage-gated sodium channels (VGSCs) were associated with pain perception after sing-port VATS. VGSCs play a key role in the initiation and transmission of action potentials in excitable cells [34]. More than 1000 disease-related mutations have been discovered in nine VGSC-encoding genes [35]. It has been widely recognized that the changes of VGSC expression are involved in the sensitization of sensory neurons in many acute and chronic pain conditions [36].

SCN11A encodes one member of the sodium channel alpha subunit gene family NaV1.9, and is highly expressed in nociceptive neurons of dorsal root ganglia and trigeminal ganglia. Mutations in this gene have been associated with hereditary pain syndromes [37]. In this study, we identified two SNPs (rs33985936, rs11709492) were associated with inadequate analgesia. The mutation of rs33985936 $(2725 \mathrm{C}>\mathrm{T})$ causes amino acid substitution Val909Ile which leads to the changes in intermolecular force of Nav1.9 [17]. Previous study reported that subjects who carrying the minor allele of rs33985936 were more sensitive to pain, while patients carrying the minor allele of rs11709492 have lower pain sensitivity [17]. This was consistent with our results that individuals who carried the rare $\mathrm{T}$ allele of rs33985936 had a 2.3-fold increase in the odds of reporting inadequate analgesia, and the rare $\mathrm{T}$ allele of rs11709492 were found to be associated with decreased risk of inadequate analgesia. 
Table 3 Distribution of clinical characteristics between patients with and without postoperative inadequate analgesia

\begin{tabular}{|c|c|c|c|}
\hline Variables & Adequate analgesia $(n=108)$ & Inadequate analgesia $(n=90)$ & $P$-Value \\
\hline Surgery time (median [IQR]) & $82.5(60-105)$ & $85(65-100)$ & 0.97 \\
\hline Anesthesia time (median [IQR]) & $110(83.5-135)$ & $110(91.5-128.5)$ & 0.89 \\
\hline Surgery end-time (median [IQR] & $15.5(13.3-18)$ & $16(14-18.6)$ & 0.27 \\
\hline Section Parts & & & 0.70 \\
\hline One part & $90(83.3 \%)$ & $76(84.4 \%)$ & \\
\hline Two parts & $15(13.9 \%)$ & $13(14.4 \%)$ & \\
\hline Three parts & $3(2.8 \%)$ & $1(1.1 \%)$ & \\
\hline Surgery Type & & & 0.49 \\
\hline Wedge resection & $17(15.7 \%)$ & $8(8.9 \%)$ & \\
\hline Segmentectomy & $21(19.4 \%)$ & $16(17.8 \%)$ & \\
\hline Lobectomy & $69(63.9 \%)$ & $65(72.2 \%)$ & \\
\hline Pneumonectomy & $1(0.9 \%)$ & $1(1.1 \%)$ & \\
\hline Lymph Node Dissection & & & 0.35 \\
\hline Yes & $91(84.3 \%)$ & $80(88.9 \%)$ & \\
\hline No & $17(15.7 \%)$ & $10(11.1 \%)$ & \\
\hline Adhesion Loosening & & & 0.28 \\
\hline Yes & $54(50.0 \%)$ & $38(42.2 \%)$ & \\
\hline No & $54(50.0 \%)$ & $52(57.8 \%)$ & \\
\hline Pathologic Diagnosis & & & 0.47 \\
\hline Low-Grade & $9(8.3 \%)$ & $12(13.3 \%)$ & \\
\hline High-Grade & $73(67.6 \%)$ & $60(66.7 \%)$ & \\
\hline Benign & $26(24.1 \%)$ & $18(20.0 \%)$ & \\
\hline
\end{tabular}

Abbreviations: IQR interquartile range

Table 4 Logistic regression analyses of associations between SNPs and risk of postoperative inadequate analgesia

\begin{tabular}{|c|c|c|c|c|c|c|c|c|c|}
\hline Gene & SNP & Model & Genotype & $\begin{array}{l}\text { Adequate } \\
\text { analgesia }\end{array}$ & $\begin{array}{l}\text { Inadequate } \\
\text { analgesia }\end{array}$ & $\begin{array}{l}\text { OR (95\% Cl) } \\
\text { unadjusted }\end{array}$ & $\begin{array}{l}P \text {-Value } \\
\text { unadjusted }\end{array}$ & $\begin{array}{l}\text { OR (95\% Cl) } \\
\text { adjusted }\end{array}$ & $\begin{array}{l}P \text {-Value } \\
\text { adjusted }\end{array}$ \\
\hline \multirow[t]{2}{*}{ ESR1 } & rs9340799 & Recessive & $A / A-G / A$ & 99 (91.7\%) & 89 (98.9\%) & 1.00 & 0.01 & 1.00 & 0.020 \\
\hline & & & $\mathrm{G} / \mathrm{G}$ & 9 (8.3\%) & $1(1.1 \%)$ & $0.12(0.02-0.99)$ & & $0.13(0.02-1.08)$ & \\
\hline \multirow[t]{2}{*}{$P 2 R Y 12$} & rs3732765 & Dominant & $\mathrm{G} / \mathrm{G}$ & $76(70.4 \%)$ & 75 (83.3\%) & 1.00 & 0.031 & 1.00 & 0.180 \\
\hline & & & G/A-A/A & 32 (29.6\%) & 15 (16.7\%) & $0.48(0.24-0.95)$ & & $0.61(0.29-1.28)$ & \\
\hline \multirow[t]{4}{*}{ SCN11A } & rs33985936 & Dominant & $\mathrm{C} / \mathrm{C}$ & $89(82.4 \%)$ & $66(73.3 \%)$ & 1.00 & 0.12 & 1.00 & 0.042 \\
\hline & & & $\mathrm{T} / \mathrm{C}-\mathrm{T} / \mathrm{T}$ & 19 (17.6\%) & $24(26.7 \%)$ & $1.70(0.86-3.37)$ & & $2.15(1.02-4.52)$ & \\
\hline & rs11709492 & Dominant & $C / C$ & $51(47.2 \%)$ & $56(62.2 \%)$ & 1.00 & 0.03 & 1.00 & 0.005 \\
\hline & & & $\mathrm{T} / \mathrm{C}-\mathrm{T} / \mathrm{T}$ & $57(52.8 \%)$ & $34(37.8 \%)$ & $0.54(0.31-0.96)$ & & $0.41(0.22-0.77)$ & \\
\hline \multirow[t]{2}{*}{ SCN1OA } & rs6795970 & Dominant & $\mathrm{G} / \mathrm{G}$ & $84(77.8 \%)$ & $59(65.6 \%)$ & 1.00 & 0.06 & 1.00 & 0.026 \\
\hline & & & $G / A-A / A$ & $24(22.2 \%)$ & 31 (34.4\%) & $1.84(0.98-3.45)$ & & $2.14(1.09-4.21)$ & \\
\hline \multirow[t]{4}{*}{ SCN9A } & rs6746030 & Dominant & $\mathrm{G} / \mathrm{G}$ & $94(87 \%)$ & $86(95.6 \%)$ & 1.00 & 0.032 & 1.00 & 0.067 \\
\hline & & & $\mathrm{G} / \mathrm{A}-\mathrm{A} / \mathrm{A}$ & $14(13 \%)$ & $4(4.4 \%)$ & $0.31(0.10-0.99)$ & & $0.35(0.10-1.16)$ & \\
\hline & $3312 \mathrm{G}>\mathrm{T}$ & Dominant & $\mathrm{G} / \mathrm{G}$ & 96 (88.9\%) & $66(73.3 \%)$ & 1.00 & 0.005 & 1.00 & 0.011 \\
\hline & & & $\mathrm{T} / \mathrm{G}-\mathrm{T} / \mathrm{T}$ & $12(11.1 \%)$ & $24(26.7 \%)$ & $2.91(1.36-6.22)$ & & $2.85(1.25-6.51)$ & \\
\hline \multirow[t]{2}{*}{ TAOK3 } & rs1277441 & Dominant & $\mathrm{T} / \mathrm{T}$ & $33(30.6 \%)$ & $40(44.4 \%)$ & 1.00 & 0.044 & 1.00 & 0.13 \\
\hline & & & $\mathrm{T} / \mathrm{C}-\mathrm{C} / \mathrm{C}$ & 75 (69.4\%) & 50 (55.6\%) & $0.55(0.31-0.99)$ & & $0.61(0.32-1.15)$ & \\
\hline
\end{tabular}

Abbreviations: $C l$ confidence intervals, ESR1 estrogen receptor 1, OR odds ratios, P2RY12 purinergic receptor P2Y12, SCN11A sodium voltage-gated channel alpha subunit 11, SCN10A sodium voltage-gated channel alpha subunit 10, SCN9A sodium voltage-gated channel alpha subunit 9 , SNP single nucleotide polymorphism, TAOK3 TAO kinase 3 
SCN1OA and SCN9A encode Nav1.8 and Nav1.7 sodium channels, respectively. They are preferentially expressed in dorsal root ganglion sensory neurons and sympathetic ganglia and significantly influence nociceptor excitability $[15,38,39]$. Recent genetic studies have identified rare and common mutations in SCN9A and SCN10A as contributory both in chronic pain conditions and postoperative pain $[15,16,39]$. Guangyou Duan et al. reported that $3312 \mathrm{G}>\mathrm{T}$ (SCN9A), a nonsynonymous SNP leading to the amino acid substitution V1104 L in human Nav1.7, was associated with postoperative inadequate analgesia [16]. Patients carrying the 3312G allele had a higher incidence of inadequate analgesia than those carrying the $3312 \mathrm{~T}$ allele. They also demonstrated an association between SCN10A rs6795970 and higher thresholds for mechanical pain in experimental pain testing [15]. However, in our study, we identified that patients with the 3312Tallele (3312G > T) and A allele (rs6795970) had a higher risk of presenting with inadequate analgesia.

As mentioned before, OPRM1and COMT play an important role in endogenous pain modulation and opioid analgesia. De Gregori $\mathrm{M}$ et al. found that genetic polymorphisms in OPRM1 (rs540825), COMT (rs4680) and ESR1 (rs9340799) have clinical effect on the morphine consumption and pain scores after major surgery [40]. The rs1799971 polymorphisms of the OPRM1 gene is related to the analgesic effect and sufentanil consumption in Chinese Han patients after radical operation of lung cancer [9]. Nevertheless the correlations were not confirmed in our present study. For ESR1 (rs9340799), the frequencies of $\mathrm{G}$ allele in patients with postoperative inadequate analgesia was less than in patients without (15\% vs. $23 \%$ ). Compared with the AA and AG genotypes, the homozygous genotype GG appeared to decrease the risk for postoperative inadequate analgesia $(\mathrm{OR}=0.12,95 \%$ CI: $0.02-0.99, p=0.01)$. After adjusting for potential confounders, although the $P$-value of the correlation was statistically significant $(p<0.05)$, the odds ratio didn't have clinical significance $(\mathrm{OR}=0.13$, 95\% CI: 0.02-1.08). So we didn't include the rs9340799 (ESR1) to the final results.

This inconsistence may partly due to the different subjects and different surgery type. The general situation of the patients included in the present study differed from previous studies, and it is known that factors such as age, race, and gender all may affect the patient's pain sensitivity [41, 42]. Then, the present study focused on patients undergoing single-port thoracoscopic surgery. The mechanisms (inflammatory pain, mechanical traction pain, and intercostal neuralgia) and degrees of postoperative pain may vary from the type of surgery. This difference may cause the same polymorphism to show inconsistent or even completely opposite results in different surgeries [20,43]. Besides, the findings identified by Guangyou Duan et al. were based on experimental pain tests performed on healthy volunteers [16]. This suggests that we should be rigorous to use these results in assessing pain sensitivity of patients after surgery. Therefore, further replication studies are warranted to confirm these findings.

There are some limitations in the present study. First, the postoperative inadequate analgesia was assessed within the first $24 \mathrm{~h}$ after surgery. In the previous study, we found that the intense pain after single-port VATS is sustained within $24 \mathrm{~h}$ especially during the first night and the first morning after surgery and majority of patients achieved satisfactory pain relief after $24 \mathrm{~h}$ [29]. So we only followed up until the first night and first morning after surgery. Second, these findings are specific to the patients underwent single-port VATS. The associations found in this study may differ in thoracotomy. Finally, due to the exploration nature of the study, the sample size was relative small and we did not replicate the study in a validation cohort. Future studies with a larger sample size may increase the power to detect differences in other candidate genes.

\section{Conclusions}

In summary, our findings suggest that polymorphisms in voltage-gated sodium channels genes play a role in the inadequate postoperative analgesia after single-port VATS. The genes and SNPs found in this study may help to identify, prevent, and targetedly treat patients with high risk of experiencing inadequate postoperative pain. This, in turn, may improve the postoperative rehabilitation and reduce short- and long-term morbidity. Future studies are warranted to confirm our findings and to determine if these associations are present in the opioid consumption analysis.

\section{Supplementary information}

Supplementary information accompanies this paper at https://doi.org/10. 1186/s12871-020-0949-6.

Additional file 1: Figure S1. LD plots of SNPS of the SCN11A gene. Identifies the linkage disequilibrium of SNPS among SCN11A gene.

Additional file 2: Table S1. Genotype and allele distributions of polymorphisms in patients with and without postoperative inadequate analgesia.

\section{Abbreviations}

ABCB1: ATP binding cassette subfamily B member 1; ADRB1: Adrenoceptor beta 1; CACNA1E: Calcium voltage-gated channel subunit alpha1 E;

Cl: Confidence intervals; COMT: Catechol-O-methyltransferase; CREB1: CAMP responsive element binding protein 1; CVC: Central venous catheterization; DRD2: Dopamine receptor D2; ESR1: Estrogen receptor 1; HWE: HardyWeinberg equilibrium; KCNJ6: Potassium voltage-gated channel subfamily J member 6; LD: Linkage disequilibrium; MAF: Minor allele frequency; OPRM1: Opioid receptor mu 1; ORs: Odds ratios; P2RX7: Purinergic receptor P2X 7; P2RY12: Purinergic receptor P2Y12; PACU: Postanesthesia care unit; PCIA: Patient-controlled intravenous; SCN10A: Sodium voltage-gated channel alpha subunit 10; SCN11A: Sodium voltage-gated channel alpha subunit 11; 
SCN9A: Sodium voltage-gated channel alpha subunit 9; SDs: Standard deviations; SNPs: Single nucleotide polymorphisms; TAOK3: TAO kinase 3; TGFB1: Transforming growth factor beta 1; TRPV1: Transient receptor potential cation channel subfamily $\vee$ member 1; UGT2B7: UDP glucuronosyltransferase family 2 member B7; VAS: Visual analog scale; VATS: Video-assisted thoracoscopic surgery; VGSCs: Voltage-gated sodium channels

\section{Acknowledgements}

Not applicable.

\section{Authors' contributions}

XX helped to conduct the study, recruited patients, collected data, analyzed the data and prepared the manuscript. YB helped to design and conduct the study, analyzed the data and revised the manuscript. KS helped to design and revised the manuscript. MY designed the study and provided revision for intellectual content and final approval of the manuscript. All authors read and approved the final manuscript

\section{Funding}

The authors declare that they have no funding.

\section{Availability of data and materials}

All relevant data and materials are presented in the manuscript.

\section{Ethics approval and consent to participate}

The Ethics Committee of the Second Affiliated Hospital of Zhejiang University School of Medicine, Hangzhou, Zhejiang, China, approved of the study protocol. All subjects signed informed consent documents prior to enrollment.

\section{Consent for publication}

Not applicable.

\section{Competing interests}

The authors declare that they have no competing interests.

Received: 4 August 2019 Accepted: 21 January 2020

Published online: 05 February 2020

\section{References}

1. Gerner P. Postthoracotomy pain management problems. Anesthesiol Clin. 2008;26:355-67 vii.

2. Rizk NP, Ghanie A, Hsu M, Bains MS, Downey RJ, Sarkaria IS, Finley DJ, Adusumilli PS, Huang J, Sima CS, et al. A prospective trial comparing pain and quality of life measures after anatomic lung resection using thoracoscopy or thoracotomy. Ann Thorac Surg. 2014;98:1160-6.

3. Bayman EO, Parekh KR, Keech J, Larson N, Vander Weg M, Brennan TJ. Preoperative patient expectations of postoperative pain are associated with moderate to severe acute pain after VATS. Pain Med. 2019;20:543-54.

4. Muehling BM, Halter GL, Schelzig H, Meierhenrich R, Steffen P, SunderPlassmann L, Orend KH. Reduction of postoperative pulmonary complications after lung surgery using a fast track clinical pathway. Eur J Cardiothorac Surg. 2008:34:174-80.

5. Kolettas A, Lazaridis G, Baka S, Mpoukovinas I, Karavasilis V, Kioumis I, Pitsiou G, Papaiwannou A, Lampaki S, Karavergou A, et al. Postoperative pain management. J Thorac Dis. 2015;7:S62-72

6. Zhang W, Chang YZ, Kan QC, Zhang LR, Lu H, Chu QJ, Wang ZY, Li ZS, Zhang J. Association of human micro-opioid receptor gene polymorphism A118G with fentanyl analgesia consumption in Chinese gynaecological patients. Anaesthesia. 2010;65:130-5.

7. Zhang F, Tong J, Hu J, Zhang H, Ouyang W, Huang D, Tang Q, Liao Q. COMT gene haplotypes are closely associated with postoperative fentanyl dose in patients. Anesth Analg. 2015;120:933-40.

8. Ochroch EA, Vachani A, Gottschalk A, Kanetsky PA. Natural variation in the mu-opioid gene OPRM1 predicts increased pain on third day after thoracotomy. Clin J Pain. 2012;28:747-54.

9. Zhao Z, Lv B, Zhao X, Zhang Y. Effects of OPRM1 and ABCB1 gene polymorphisms on the analgesic effect and dose of sufentanil after thoracoscopic-assisted radical resection of lung cancer. Biosci Rep. 2019;39: BSR20181211.
10. Sastre JA, Varela G, Lopez M, Muriel C, Gonzalez-Sarmiento R. Influence of uridine diphosphate-glucuronyltransferase 2B7 (UGT2B7) variants on postoperative buprenorphine analgesia. Pain Pract. 2015;15:22-30.

11. Ma J, Li W, Chai Q, Tan X, Zhang K. Correlation of P2RX7 gene rs 1718125 polymorphism with postoperative fentanyl analgesia in patients with lung cancer. Medicine. 2019;98:e14445.

12. Semyonov M, Fedorina E, Grinshpun J, Dubilet M, Refaely Y, Ruderman L, Koyfman L, Friger M, Zlotnik A, Klein M, et al. Ultrasound-guided serratus anterior plane block for analgesia after thoracic surgery. J Pain Res. 2019;12: $953-60$.

13. George SZ, Wu SS, Wallace MR, Moser MW, Wright TW, Farmer KW, Greenfield WH 3rd, Dai Y, Li H, Fillingim RB. Biopsychosocial influence on shoulder pain: influence of genetic and psychological combinations on twelve-month postoperative pain and disability outcomes. Arthritis Care Res. 2016;68:1671-80.

14. Li J, Wei Z, Zhang J, Hakonarson H, Cook-Sather SD. Candidate gene analyses for acute pain and morphine analgesia after pediatric day surgery: African American versus European Caucasian ancestry and dose prediction limits. Pharmacogenomics J. 2019;19:570-81.

15. Duan G, Han C, Wang Q, Guo S, Zhang Y, Ying Y, Huang P, Zhang L, Macala $L$, Shah P, et al. A SCN10A SNP biases human pain sensitivity. Mol Pain. 2016;12:1744806916666083.

16. Duan G, Xiang G, Zhang X, Yuan R, Zhan H, Qi D. A single-nucleotide polymorphism in SCN9A may decrease postoperative pain sensitivity in the general population. Anesthesiology. 2013;118:436-42.

17. Sun J, Duan G, Li N, Guo S, Zhang Y, Ying Y, Zhang M, Wang Q, Liu JY, Zhang X. SCN11A variants may influence postoperative pain sensitivity after gynecological surgery in Chinese Han female patients. Medicine. 2017;96: e8149.

18. Nishizawa D, Nagashima M, Katoh R, Satoh Y, Tagami M, Kasai S, Ogai Y Han W, Hasegawa J, Shimoyama N, et al. Association between KCNJ6 (GIRK2) gene polymorphisms and postoperative analgesic requirements after major abdominal surgery. PLoS One. 2009;4:e7060.

19. Kim H, Neubert JK, San Miguel A, Xu K, Krishnaraju RK, ladarola MJ, Goldman $D$, Dionne RA. Genetic influence on variability in human acute experimental pain sensitivity associated with gender, ethnicity and psychological temperament. Pain. 2004;109:488-96.

20. Ide S, Nishizawa D, Fukuda K, Kasai S, Hasegawa J, Hayashida M, Minami M, Ikeda K. Association between genetic polymorphisms in Ca(v)2.3 (R-type) $\mathrm{Ca} 2+$ channels and fentanyl sensitivity in patients undergoing painful cosmetic surgery. PloS one. 2013;8:e70694.

21. Tan EC, Lim EC, Ocampo CE, Allen JC, Sng BL, Sia AT. Common variants of catechol-O-methyltransferase influence patient-controlled analgesia usage and postoperative pain in patients undergoing total hysterectomy. Pharmacogenomics J. 2016;16:186-92.

22. Jaaskelainen $S K$, Lindholm $P$, Valmunen $T$, Pesonen $U$, Taiminen $T$, Virtanen A, Lamusuo S, Forssell H, Hagelberg N, Hietala J, et al. Variation in the dopamine D2 receptor gene plays a key role in human pain and its modulation by transcranial magnetic stimulation. Pain. 2014;155:2180-7.

23. Sumitani M, Nishizawa D, Nagashima M, Ikeda K, Abe H, Kato R, Ueda H, Yamada Y. Japanese TRCPrg: association between polymorphisms in the Purinergic P2Y12 receptor gene and Severity of both Cancer pain and postoperative pain. Pain Med. 2018;19:348-54.

24. Moriyama A, Nishizawa D, Kasai S, Hasegawa J, Fukuda K, Nagashima M, Katoh R, Ikeda K. Association between genetic polymorphisms of the beta1adrenergic receptor and sensitivity to pain and fentanyl in patients undergoing painful cosmetic surgery. J Pharmacol Sci. 2013;121:48-57.

25. An X, Fang J, Lin Q, Lu C, Ma Q, Qu H. New evidence for involvement of ESR1 gene in susceptibility to Chinese migraine. J Neurol. 2017;264:81-7.

26. Cook-Sather SD, Li J, Goebel TK, Sussman EM, Rehman MA, Hakonarson H. TAOK3, a novel genome-wide association study locus associated with morphine requirement and postoperative pain in a retrospective pediatric day surgery population. Pain. 2014;155:1773-83.

27. Somogyi AA, Sia AT, Tan EC, Coller JK, Hutchinson MR, Barratt DT. Ethnicitydependent influence of innate immune genetic markers on morphine PCA requirements and adverse effects in postoperative pain. Pain. 2016;157: 2458-66.

28. Nishizawa D, Fukuda K, Kasai S, Hasegawa J, Aoki Y, Nishi A, Saita N, Koukita $Y$, Nagashima M, Katoh R, et al. Genome-wide association study identifies a potent locus associated with human opioid sensitivity. Mol Psychiatry. 2014; 19:55-62. 
29. Bai Y, Sun K, Xing X, Zhang F, Sun N, Gao Y, Zhu L, Yao J, Fan J, Yan M. Postoperative analgesic effect of hydromorphone in patients undergoing single-port video-assisted thoracoscopic surgery: a randomized controlled trial. J Pain Res. 2019;12:1091-101.

30. Graves H, Rayburn AL, Gonzalez-Hernandez JL, Nah G, Kim DS, Lee DK Validating DNA Polymorphisms Using KASP Assay in Prairie Cordgrass (Spartina pectinata Link) Populations in the U.S. Front Plant Sci. 2015;6:1271.

31. He C, Holme J, Anthony J. SNP genotyping: the KASP assay. Methods Mol Biol. 2014;1145:75-86.

32. Sole X, Guino E, Valls J, Iniesta R, Moreno V. SNPStats: a web tool for the analysis of association studies. Bioinformatics. 2006;22:1928-9.

33. Wang H, Li S, Liang N, Liu W, Liu H, Liu H. Postoperative pain experiences in Chinese adult patients after thoracotomy and video-assisted thoracic surgery. J Clin Nurs. 2017;26:2744-54.

34. Xu L, Ding X, Wang T, Mou S, Sun H, Hou T. Voltage-gated sodium channels: structures, functions, and molecular modeling. Drug Discov Today. 2019;24: 1389-97.

35. Huang W, Liu M, Yan SF, Yan N. Structure-based assessment of diseaserelated mutations in human voltage-gated sodium channels. Protein Cell. 2017:8:401-38

36. Bennett DL, Clark AJ, Huang J, Waxman SG, Dib-Hajj SD. The role of voltagegated sodium channels in pain signaling. Physiol Rev. 2019;99:1079-151.

37. Dib-Hajj SD, Black JA, Waxman SG. NaV1.9: a sodium channel linked to human pain. Nat Rev Neurosci. 2015;16:511-9.

38. Garrison SR, Weyer AD, Barabas ME, Beutler BA, Stucky CL. A gain-offunction voltage-gated sodium channel 1.8 mutation drives intense hyperexcitability of A- and C-fiber neurons. Pain. 2014;155:896-905.

39. Yang Y, Wang Y, Li S, Xu Z, Li H, Ma L, Fan J, Bu D, Liu B, Fan Z, et al. Mutations in SCN9A, encoding a sodium channel alpha subunit, in patients with primary erythermalgia. J Med Genet. 2004;41:171-4.

40. De Gregori M, Diatchenko L, Ingelmo PM, Napolioni V, Klepstad P, Belfer I, Molinaro V, Garbin G, Ranzani GN, Alberio G, et al. Human genetic variability contributes to postoperative morphine consumption. J Pain. 2016;17:628-36.

41. Riley JL 3rd, Cruz-Almeida Y, Glover TL, King CD, Goodin BR, Sibille KT, Bartley EJ, Herbert MS, Sotolongo A, Fessler BJ, et al. Age and race effects on pain sensitivity and modulation among middle-aged and older adults. J Pain. 2014;15:272-82

42. Sato H, Droney J, Ross J, Olesen AE, Staahl C, Andresen T, Branford R, Riley J, Arendt-Nielsen L, Drewes AM. Gender, variation in opioid receptor genes and sensitivity to experimental pain. Mol Pain. 2013;9:20.

43. Amano K, Nishizawa D, Mieda T, Tsujita M, Kitamura A, Hasegawa J, Inada E, Hayashida M, Ikeda K. Opposite associations between the rs3845446 singlenucleotide polymorphism of the CACNA1E gene and Postoperative painrelated phenotypes in gastrointestinal surgery versus previously reported Orthognathic surgery. J Pain. 2016;17:1126-34.

\section{Publisher's Note}

Springer Nature remains neutral with regard to jurisdictional claims in published maps and institutional affiliations.

Ready to submit your research? Choose BMC and benefit from:

- fast, convenient online submission

- thorough peer review by experienced researchers in your field

- rapid publication on acceptance

- support for research data, including large and complex data types

- gold Open Access which fosters wider collaboration and increased citations

- maximum visibility for your research: over $100 \mathrm{M}$ website views per year

At $\mathrm{BMC}$, research is always in progress.

Learn more biomedcentral.com/submissions 